\title{
Study on Key Factors of Adsorption of Phosphorus by Steel Slag Filter Based on Response Surface Method
}

\author{
Jiabin Wang ${ }^{1, *}$, Xiaoyu Wang ${ }^{1}$, Liping Qiu ${ }^{1}$, Tianhang $\operatorname{Li}^{1}$,Cong Yu ${ }^{1}$ \\ 1 School of Civil Engineering \& Architecture, University of Jinan, NO.336, Nanxinzhuang West Road., Jinan 250022, P.R.China
}

\begin{abstract}
Excessive phosphorus emission is one of the important reasons for the eutrophication of water. At the same time, phosphorus is a significant mineral resource. In this paper, the response surface method is used to study the key influencing factors of phosphorus removal by steel slag filter and its action. Four factors affecting the dosage, initial $\mathrm{pH}$, reaction time and calcium-phosphorus molar ratio were selected. The phosphorus removal was used as the response value. The interaction between various factors was established by Box-Behnken response surface analysis. The optimal conditions were determined by equation regression analysis: dosage $=2 \mathrm{~cm}^{3}$; initial $\mathrm{pH}=7$; molar ratio of calcium to phosphorus was 2:1; reaction time $=2 \mathrm{~h}$.
\end{abstract}

\section{Introduction}

In recent years, the phenomenon of eutrophication of water bodies in China has become more and more serious. The excessive emission of phosphorus is one of the main factors causing eutrophication of water bodies. The traditional methods of phosphorus removal include chemical methods and biological methods. Phosphorus recovery is difficult, and the adsorption method is receiving increasing attention due to its advantages in phosphorus recovery.

Studies have shown that the adsorption method of phosphorus removal is the use of porous or large specific surface area of solid matter on the phosphate ion in water, through physical adsorption, ion exchange, chemical reaction or surface precipitation and other processes to achieve phosphorus separation ${ }^{[1]}$. Our previous studies have found that, in order to produce raw materials for steel plant waste slag unburned slag type filter having good adsorption phosphorus removal ${ }^{[2-6]}$, the present study is to response surface method, is used to screen unburned slag the key adsorption filter phosphorus removal by impact factor, to explore its regular pattern, to explore the optimum operating parameters of slag adsorption filter phosphorus removal.

\section{Materials and methods}

\subsection{Test Material}

In this experiment, the steel slag of a steelmaking plant in Jinan City is selected as the raw material, and the XRD test results of the steel slag are shown in Figure1 below. Its main component is $\mathrm{CaO}$ accounted for $57.78 \%$ of the steel slag composition, followed by $\mathrm{SiO}_{2}$ accounted for $19.90 \%$ of the total composition, and then $\mathrm{Al}_{2} \mathrm{O}_{3}$ accounted for $7.45 \%$ of the total composition, $\mathrm{Fe}_{2} \mathrm{O}_{3}$ accounted for $5.78 \%$ of the total composition, and $\mathrm{MgO}$ accounted for $4.03 \%$ of the total composition. $\mathrm{SO}_{3}$ accounted for $2.81 \%$ of total composition, $\mathrm{MnO}$ accounted for $0.52 \%, \mathrm{TiO}_{2}$ accounted for $0.52 \%, \mathrm{~K}_{2} \mathrm{O}$ accounted for $0.52 \%, \mathrm{P}_{2} \mathrm{O}_{5}$ accounted for $0.24 \%, \mathrm{Na}_{2} \mathrm{O}$ accounted for $0.20 \%, \mathrm{Cl}$ accounted for $0.06 \%, \mathrm{~V}_{2} \mathrm{O}_{5}$ accounted for $0.05 \%, \mathrm{SrO}$ accounted for $0.05 \%$, and $\mathrm{Cr}_{2} \mathrm{O}_{3}$ accounted for $0.04 \%$. $\mathrm{ZrO}_{2}$ accounts for $0.03 \%$.

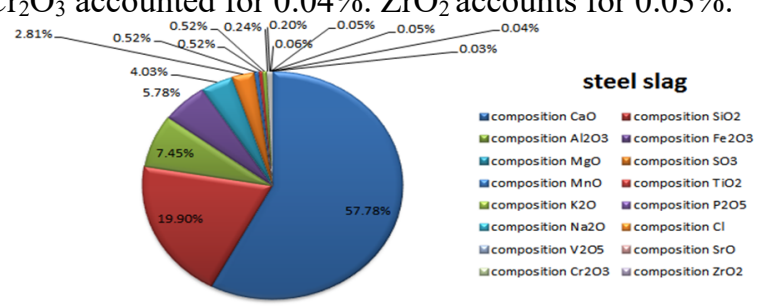

Fig.1 Composition of steel slag

\subsection{Experiment method}

\subsubsection{Test plan}

In this experiment, artificial phosphorus was used to simulate phosphorus-containing wastewater. The water-dispensing drug was $0.2769 \mathrm{~g} \mathrm{CaCl}_{2}$ after drying, and $0.4394 \mathrm{~g}$ of $\mathrm{KH}_{2} \mathrm{PO}_{4}$. The concentration of calcium and phosphorus in the solution was $100 \mathrm{mg} / \mathrm{l}$. In the experiment, $200 \mathrm{ml}$ of phosphorus-containing wastewater was taken in an Erlenmeyer flask, and the $\mathrm{pH}$ was adjusted to $7.00, \mathrm{~T}=20^{\circ} \mathrm{C}$. Referring to the steel slag (bulk density $=0.8037 \mathrm{~g} / \mathrm{cm}^{3}$ ), each group is weighed into $1.0,2.0,3.0,4.0,5.0 \mathrm{~cm}^{3}$ and placed in 5 conical flasks, and shaken in a constant temperature shaking box for $3 \mathrm{~h}$. After taking out, the concentration of phosphorus

\footnotetext{
* Corresponding author: cea_wangjb@ujn.edu.cn
} 
in the water sample and the $\mathrm{pH}$ value of the effluent were measured by filtration through a membrane to analyze the phosphorus removal efficiency.

\subsubsection{Response surface test}

Minyu Zuo, et.al and Jianguo Li, et.al ${ }^{[10-11]}$ used the response surface method to study the influence factors affecting the adsorption and dephosphorization performance of steel slag filter materials, and obtained the calcium content and initial $\mathrm{pH}$ value of the filter material. Both factors have a significant effect on phosphorus removal performance. Jibing Xiong, et.al [12] used a single factor variable experimental method to study the effect of steel slag on the removal of phosphate from wastewater, and obtained the $\mathrm{pH}$ value affecting the removal efficiency of phosphate. Li Yanbo, et.al ${ }^{[13]}$ designed a single factor experiment to study the main influencing factors of phosphorus removal efficiency of steel slag. The conclusion is that the initial $\mathrm{pH}$, the dosage of filter material, the reaction time and the initial phosphorus concentration will affect the phosphorus removal efficiency to different extents. In the filter material preparation and sewage adsorption phosphorus removal test, Zheng Jun ,et.al ${ }^{[14]}$ explored the key factors affecting the removal of phosphorus from the filter material, and obtain the optimal $\mathrm{pH}$ value, dosage and initial phosphorus concentration best. It was found that two factors of $\mathrm{Ca}^{2+}$ and $\mathrm{pH}$ affect the phosphorus removal effectively. The filter material has the function of retaining, adsorbing and inducing crystallization ${ }^{[7-9]}$, and the phosphate and calcium ions in the wastewater will precipitate, which will promote the crystallization of the crystal, so the adsorption capacity of the filter material for phosphorus is more remarkable. Therefore, it can be seen that the four key factors are the filter feed amount, initial $\mathrm{pH}$, reaction time and calcium-phosphorus molar ratio (initial concentration of phosphorus), and the range of the items is as follows: dosage 2-4 $\mathrm{cm}^{3}$; initial $\mathrm{pH}=5-7$; reaction time: $1-3 \mathrm{~h}$; Ca: $\mathrm{P}$ (molar ratio) 1.0-3.0.

The response surface analysis test plan was designed by taking three levels from each factor. The factors and levels are shown in Table 1.

Table1. Factors and levels of response surface analysis

\begin{tabular}{ccccc}
\hline \multirow{2}{*}{ Level } & \multicolumn{4}{c}{ Factor } \\
\cline { 2 - 5 } & $\begin{array}{c}\text { Dosing } \\
\text { amount/cm3 }\end{array}$ & $\begin{array}{c}\text { Initial } \\
\mathrm{pH}\end{array}$ & $\mathrm{Ca}: \mathrm{P}$ & $\begin{array}{c}\text { Reaction } \\
\text { time } / \mathrm{h}\end{array}$ \\
\hline-1 & 2.0 & 5.0 & 1.0 & 1.0 \\
0 & 3.0 & 6.0 & 2.0 & 2.0 \\
1 & 4.0 & 7.0 & 3.0 & 3.0 \\
\hline
\end{tabular}

\section{Experimental results and analysis}

\subsection{Box-Behnken test design}

This experiment uses the response surface method combined with the orthogonal experimental idea, and then according to the selection of suitable filter material dosage range $2-4 \mathrm{~cm}^{3}$, initial $\mathrm{pH}$ range 5-7, calcium-phosphorus molar ratio 1.0-3.0, reaction time $1-3 \mathrm{~h}$, and four factors and response values of the experimental design are shown by Box-Behnken test design in Table 2:

Table 2. Response surface experimental scheme and results

\begin{tabular}{cccccc}
\hline $\begin{array}{c}\text { serial } \\
\text { number }\end{array}$ & $\begin{array}{c}\text { A: Dosing } \\
\text { amount } \\
\text { /cm3 }\end{array}$ & $\begin{array}{c}\text { B: } \\
\text { Initial } \\
\text { pH }\end{array}$ & $\begin{array}{c}\text { C: } \\
\text { Ca:P }\end{array}$ & $\begin{array}{c}\text { D: } \\
\text { Reaction } \\
\text { time/h }\end{array}$ & $\begin{array}{c}\text { Phosphorus } \\
\text { removal /mg }\end{array}$ \\
\hline 1 & 4 & 5 & 2 & 2 & 1.574 \\
2 & 3 & 5 & 2 & 1 & 1.52 \\
3 & 3 & 7 & 1 & 2 & 1.942 \\
4 & 2 & 6 & 3 & 2 & 1.921 \\
5 & 3 & 6 & 3 & 1 & 1.875 \\
6 & 3 & 6 & 2 & 2 & 1.9 \\
7 & 2 & 5 & 2 & 2 & 1.531 \\
8 & 2 & 6 & 2 & 1 & 1.9 \\
9 & 3 & 5 & 1 & 2 & 1.5 \\
10 & 3 & 7 & 3 & 2 & 1.965 \\
11 & 3 & 5 & 3 & 2 & 1.5 \\
12 & 4 & 6 & 2 & 3 & 1.97 \\
13 & 3 & 6 & 2 & 2 & 1.94 \\
14 & 3 & 6 & 2 & 2 & 1.94 \\
15 & 4 & 6 & 2 & 1 & 1.969 \\
16 & 2 & 6 & 2 & 3 & 1.931 \\
17 & 3 & 7 & 2 & 1 & 1.977 \\
18 & 3 & 7 & 2 & 3 & 2.01 \\
19 & 3 & 6 & 1 & 3 & 1.875 \\
20 & 3 & 6 & 2 & 2 & 1.9 \\
21 & 3 & 5 & 2 & 3 & 1.54 \\
22 & 3 & 6 & 1 & 1 & 1.875 \\
23 & 4 & 6 & 1 & 2 & 1.96 \\
24 & 3 & 6 & 3 & 3 & 1.88 \\
25 & 2 & 7 & 2 & 2 & 1.94 \\
26 & 4 & 7 & 2 & 2 & 2 \\
27 & 3 & 6 & 2 & 2 & 1.9 \\
28 & 4 & 6 & 3 & 2 & 1.96 \\
\hline 29 & 2 & 6 & 1 & 2 & 1.92 \\
\hline & 3 & 5 & 5 & 2 & 2 \\
\hline
\end{tabular}

Multivariate nonlinear fitting of the data in the table yields a quaternary quadratic regression model:

phosphorus removal $=-5.24479-0.16108 \times$ dosage +

$2.20667 \times$ initial $\mathrm{pH}+0.050833$

$\times(\mathrm{Ca}: \mathrm{P})+0.018167 \times$ Reaction

time $+4.25000 \mathrm{E}-003 \times$ dosing amount $\times$ initial

$\mathrm{pH}-2.50000 \mathrm{E}-004 \times$ dosing

amount $\times(\mathrm{Ca}: \mathrm{P})-7.50000 \mathrm{E}-003 \times$ dosing amount $\times$ reaction time $+5.75000 \mathrm{E}-003 \times$ initial $\mathrm{pH}$

$\times(\mathrm{Ca}: \mathrm{P})+3.25000 \mathrm{E}-003 \times$ initial $\mathrm{pH} \times$ reaction

time $+1.25000 \mathrm{E}-003 \times(\mathrm{Ca}: \mathrm{P}) \times$ reaction

time $+0.029208 \times$ dosing amount $2-0.16792 \times$ initial

pH2-0.021167×(Ca:P)2-2.54167E-003 $\times$ reaction time 2 . 
Table 3 .Test plan and model analysis table

\begin{tabular}{|c|c|c|c|c|c|c|}
\hline Source & Sum of Squares & $\mathrm{df}$ & Mean Squares & $\begin{array}{c}\mathrm{F} \\
\text { Value }\end{array}$ & P-value Prob $>F$ & Significant \\
\hline Model & 0.81 & 14 & 0.058 & 105.11 & $<0.0001$ & significant \\
\hline $\begin{array}{l}\text { A- Dosing } \\
\text { amount }\end{array}$ & $7.01 \mathrm{E}-03$ & 1 & $7.01 \mathrm{E}-03$ & 12.69 & 0.0031 & \\
\hline $\begin{array}{c}\text { B- Initial } \\
\text { pH }\end{array}$ & 0.59 & 1 & 0.59 & 1075.2 & $<0.0001$ & \\
\hline C-Ca:P & $7.01 \mathrm{E}-05$ & 1 & 7.01E-05 & 0.13 & 0.7269 & \\
\hline $\begin{array}{c}\text { D- Reaction } \\
\text { time }\end{array}$ & $6.75 \mathrm{E}-04$ & 1 & $6.75 \mathrm{E}-04$ & 1.22 & 0.2875 & \\
\hline $\mathrm{AB}$ & 7.23E-05 & 1 & $7.23 \mathrm{E}-05$ & 0.13 & 0.7229 & \\
\hline $\mathrm{AC}$ & $2.50 \mathrm{E}-07$ & 1 & $2.50 \mathrm{E}-07$ & 4.53E-04 & 0.9833 & \\
\hline $\mathrm{AD}$ & $2.25 \mathrm{E}-04$ & 1 & $2.25 \mathrm{E}-04$ & 0.41 & 0.5335 & \\
\hline $\mathrm{BC}$ & $1.32 \mathrm{E}-04$ & 1 & 1.32E-04 & 0.24 & 0.6321 & \\
\hline $\mathrm{BD}$ & 4.23E-05 & 1 & $4.23 \mathrm{E}-05$ & 0.077 & 0.7861 & \\
\hline $\mathrm{CD}$ & $6.25 \mathrm{E}-06$ & 1 & $6.25 \mathrm{E}-06$ & 0.011 & 0.9168 & \\
\hline $\mathrm{A}^{\wedge} 2$ & $5.53 \mathrm{E}-03$ & 1 & $5.53 \mathrm{E}-03$ & 10.02 & 0.0069 & \\
\hline $\mathrm{B}^{\wedge} 2$ & 0.18 & 1 & 0.18 & 331.26 & $<0.0001$ & \\
\hline $\mathrm{C}^{\wedge} 2$ & $2.91 \mathrm{E}-03$ & 1 & 2.91E-03 & 5.26 & 0.0378 & \\
\hline $\mathrm{D}^{\wedge} 2$ & 4.19E-05 & 1 & 4.19E-05 & 0.076 & 0.787 & \\
\hline Residual & 7.73E-03 & 14 & $5.52 \mathrm{E}-04$ & - & - & \\
\hline Lack of Fit & 5.81E-03 & 10 & $5.81 \mathrm{E}-04$ & 1.21 & 0.4623 & not significant \\
\hline Pure Error & $1.92 \mathrm{E}-03$ & 4 & $4.80 \mathrm{E}-04$ & - & - & \\
\hline Cor Total & 0.82 & 28 & - & - & - & \\
\hline
\end{tabular}

Note: $\mathrm{P}<0.0001$ indicates extremely significant, $\mathrm{P}<$ 0.05 indicates significant, and $\mathrm{P}>0.05$ indicates no significant.

It can be seen from Table 4 that the response value of each parameter of the mathematical model is "significant", the significance is good, and "Lack of Fit" is "not significant". That is, the established model is in line with the actual experiment. The Ca:P (molar ratio) $\operatorname{Pr}=0.7269>$ the reaction time $\operatorname{Pr}=0.2875>$ the dosage of $\operatorname{Pr}=0.0031>$ the initial $\mathrm{pH}$ value $\operatorname{Pr}<0.0001$. It can be seen that the degree of influence of each factor on the magnetic field strength is initial $\mathrm{pH}>$ filter feed amount $>$ reaction time $>\mathrm{Ca}: \mathrm{P}$ (molar ratio).

\subsection{Response surface analysis}


Fig.2. Response surface map and contour map of initial $\mathrm{pH}$ and $\mathrm{Ca}: \mathrm{P} \quad\left(\right.$ dosing amount $=3 \mathrm{~cm}^{3}$, reaction time $\left.=2 \mathrm{~h}\right)$
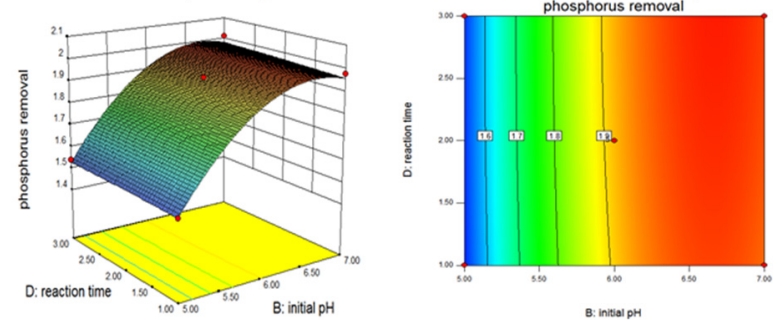

Fig.3. Response surface plot and contour plot of initial $\mathrm{pH}$ and reaction time (dosing amount $=3 \mathrm{~cm}^{3}, \mathrm{Ca}: \mathrm{P}=2$ )

In the response surface diagram of Fig. 2, when the $\mathrm{pH}$ is in the range of 5-7, the removal amount of phosphorus shows a significant increase with the increase of $\mathrm{pH}$ value. The regression analysis of model variance $(\mathrm{P}<0.0001)$ indicates the removal of phosphorus by $\mathrm{pH}$, which impact is extremely significant. When Ca:P was changed within the range of $1-3$, the difference between the removal of phosphorus by Ca:P (molar ratio) was not significant $(\mathrm{P}>0.05)$. The interaction between the two is very significant, and the effect of initial $\mathrm{pH}$ on phosphorus removal is much greater than the effect of $\mathrm{Ca}: \mathrm{P}$ (molar ratio). Figure 3 reflects the interaction between the initial $\mathrm{pH}$ and the reaction time. The surface map and contour plot analysis plus the reaction time of $1-3 \mathrm{~h}$, the variance model analysis table $(\mathrm{P}>0.05)$, the difference effect is not significant. Therefore, the effect of initial $\mathrm{pH}$ on phosphorus removal is much greater than the reaction time. At the same time, the optimum initial $\mathrm{pH}=7$ can be determined.
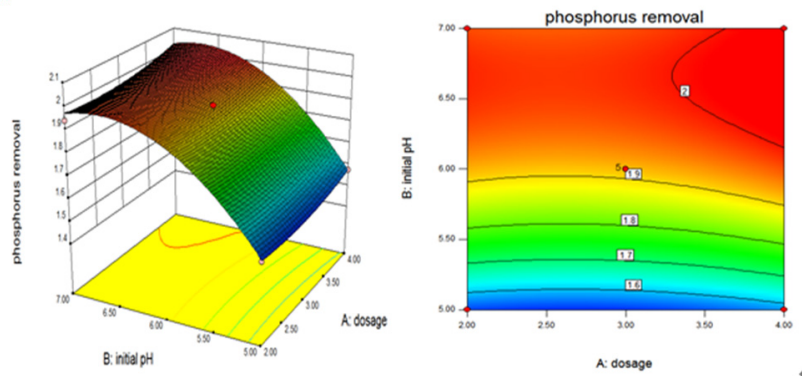

Fig.4. Response surface plot and contour plot of dosage and initial $\mathrm{pH}(\mathrm{Ca}: \mathrm{P}=2 \mathrm{~h}$, reaction time $=2 \mathrm{~h})$

It can be seen from Fig. 4 that when the $\mathrm{pH}$ is in the range of 5-7, the amount of phosphorus removed shows a significant increase with the increase of $\mathrm{pH}$. Since the steel slag containing a large amount of calcium is in the crystal precipitation reaction, an increase in $\mathrm{pH}$ promotes the induction of the crystallization reaction, so that the reaction proceeds in the positive direction. The interaction between the initial $\mathrm{pH}$ of the solution and the dosage is very significant, and the effect of $\mathrm{pH}$ on the amount of phosphorus removed is greater than the effect of the dosage. At the same time, in combination with Fig. 3 and Fig. 4, the optimal reaction time $=2 \mathrm{~h}$ can be determined. 

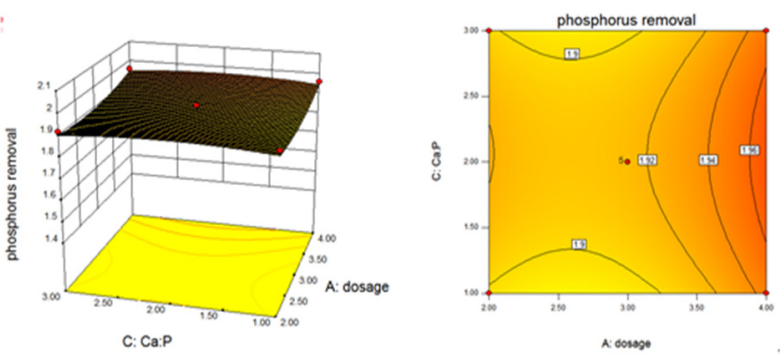

Fig.5. Response surface and contour plot of dosage and $\mathrm{Ca}: \mathrm{P}$ (initial $\mathrm{pH}=7$, reaction time $=2 \mathrm{~h}$ )
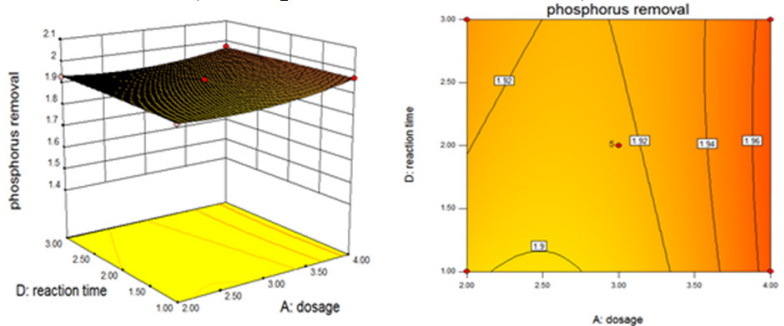

Fig.6. Response surface and contour map of the dosage and reaction time (initial $\mathrm{pH}=7, \mathrm{Ca}: \mathrm{P}=2$ )

It can be seen from Fig. 5 that when the dosage is in the range of 2-4 $\mathrm{cm}^{3}$, the amount of phosphorus removed decreases first and then increases with the increase of the dosage, and the optimum dosage $=2 \mathrm{~cm}^{3}$ can be selected. The influence of Ca:P (molar ratio) on the removal amount of phosphorus is basically consistent with the trend of dosage. The significance of the difference in the analysis of the variance model is also shown: the dosage of $\mathrm{P}=0.0031<0.05$, the significance of $\mathrm{Ca}: \mathrm{P}$ $=0.7269>0.05$. Therefore, the effect of dosage is greater than the effect of Ca:P. It can be seen from Fig. 6 that when the reaction time within 1-3 $\mathrm{h}$, the removal amount of phosphorus does not change significantly, and the difference in the effect of phosphorus removal $(\mathrm{P}>0.05)$ is not significant. At the same time, it can be seen that the interaction between the two is not very significant, but the effect of the dosage on the amount of phosphorus removal is greater than the effect of the reaction time.
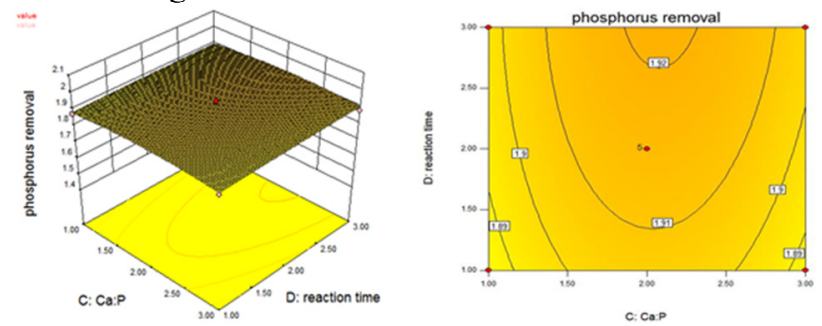

Fig.7. Ca: Response surface curve and contour map of $\mathrm{P}$ and reaction time (when dosage $=3 \mathrm{~cm}^{3}$, initial $\mathrm{pH}=6$ )

When the Ca:P (molar ratio) is in the range of $1-3$, the amount of phosphorus removal increases first and then decreases with the increase of $\mathrm{Ca}: \mathrm{P}$ (molar ratio), and when the reaction time changes within 1-3 hours, there was no significant change in the amount of phosphorus removal. The difference between the reaction time and the response value $(\mathrm{P}=0.28705>0.05)$ was not significant. It can be concluded from Fig.7 that the interaction between the two is not obvious, so the degree of influence of calcium and phosphorus molar ratio and reaction time is small. At the same time, the optimal calcium to phosphorus molar ratio is $\mathrm{Ca}: \mathrm{P}=2$.

\section{Conclusions}

1) Taking the removal rate of phosphorus as the response value, the dosage of the filter material, the initial $\mathrm{pH}$, the reaction time, and the molar ratio of calcium to phosphorus as the key factors, a multivariate quadratic response surface regression model for the adsorption and phosphorus removal of the steel slag filter material is obtained. The effect of the model is extremely significant, the missing term is not significant, the degree of variance is high, and the accuracy is high.

2) The interaction between initial $\mathrm{pH}$ and steel slag dosage is the largest, and the interaction between initial $\mathrm{pH}$ and reaction time is second, and the interaction between initial $\mathrm{pH}$ and $\mathrm{Ca}: \mathrm{P}$ (molar ratio) is the smallest. According to the regression model analysis of variance, the order of influence of various factors on phosphorus removal rate is as follows: initial $\mathrm{pH}>$ filter feed amount $>$ reaction time $>\mathrm{Ca}: \mathrm{P}$ (molar ratio).

3) The optimal conditions for the key factors affecting the adsorption of phosphorus by steel slag were analyzed by response surface methodology. The initial $\mathrm{pH}=7$, the steel slag dosage $=2 \mathrm{~cm}^{3}, \mathrm{Ca}: \mathrm{P}=2$, and the reaction time $=2 \mathrm{~h}$, the removal efficiency of the steel slag to phosphorus is optimal.

\section{Acknowledgment}

This work was supported by the Higher Education Science and Technology Plan of Shandong Province (J17KA198).

\section{References}

1. Yang Jizhen, Chen Shuiping, Xia Shibin,et.al. Study on phosphorus removal from high phosphorus concentration ore-dressing wastewater by steel slag $[\mathrm{J}]$.Water supply and drainage. 46(07):153-157(2010)

2. Zheng Jun, MA Lulu, Liu Baohe. Experimental Study on the removal of phosphate by porous calcium silicate bed [J]. Environmental Pollution and Control, 35(08) : 28-32 (2013)

3. Peng Xihua,Ma Xi-jun,Liu Xuemei, et.al. Study on treatment of low concentrated phosphorus containing wastewater by modified fly ash $[\mathrm{J}]$.Environmental Pollution and Control,34(01): 52-55(2012)

4. Wang Xinyong, Chen Xuechu, He Shengbing, et.al.Recovery of phosphorous from wastewater by calcium silicate hydrate[J].Industrial Water and Wastewater,42(4):51-54(2011)

5. Zhao Y, Yue Q, Li Q, et al. Characterization of red mud granular adsorbent (RMGA) and its performance on phosphate removal from aqueous solution[J]. Chemical Engineering Journal, 193-194(12):161-168(2012)

6. Qin Juanjuan.The study of adsorption characteristics of pollutants in saline wastewater by constructed 
wetland substrates[D]. Ocean University of China, (2014).

7. Ma Honglin, He Tao, Hong Lei, et al. Optimization of the adsorption of phosphorus by water plantsludge using response surface methodology [J]. Journal of Environmental Engineering, 9 (2) : 546-552(2015)

8. Xiong J, He Z, Mahmood Q, et al. Phosphate removal from solution using steel slag through magnetic separation[J]. Journal of Hazardous Materials, 152(1):211-5(2008)

9. Yubo, Xiuyun, Fangbian, et al. Removal of phosphate from wastewater using alkaline residue[J]. Journal of Environmental Sciences, 26(5):970-980(2014)

10. Zuo M, Renman G, Gustafsson $\mathrm{J}$ P, et al. Phosphorus removal performance and speciation in virgin and modified argon oxygen decarburisation slag designed for wastewater treatment.[J]. Water Research, 87:271-281(2015)

11. Li J, Wu B, Zhou T, et al. Preferential removal of phosphorus using modified steel slag and cement combination for its implications in engineering applications $[\mathrm{J}]$. Environmental Technology \& Innovation, 10(2018).

12. Xiong J, He Z, Mahmood Q, et al. Phosphate removal from solution using steel slag through magnetic separation[J]. Journal of Hazardous Materials, 152(1):211-5(2018)

13. Li Yanbo, Qiu Liping, Wang Guangwei, et.al.Phosphorus Removal Efficiency of Hydrothermally Modified Granular Steel Slag [J]. China Water Supply and Drainage, 27(09): 74-77(2011)

14. Gustafsson J P, Renman A, Renman G, et al. Phosphate removal by mineral-based sorbents used in filters for small-scale wastewater treatment[J]. Water Research, 42(1-2):189-197(2008) 